\title{
Research of Development Strategy of Mass Sports in China under Goal of Overall Construction of Well-being Society
}

\author{
Xianfu Wang \\ Sports College of Zhongzhou University, Zhengzhou, Henan, China, 450044 \\ Wxf5276@126.com
}

\begin{abstract}
Development of mass sports is an effective measure of fully building well-being society, improving national quality and enhancing comprehensive national strength. With document-data method and in the basis of interpretation of overall construction of well-being society, the general development situation of mass sports is expatiated to find out the outstanding problems in mass sports development, then, the development trend of mass sports in China is discussed, and its development strategy is put forward.
\end{abstract}

Keywords-well-being society; mass sports; Chinese characteristics; development

\section{INTRODUCTION}

At present, our country is facing an "unprecedented challenges": the well-being society should be completed in all-round way as scheduled in 2020. Mass sports is an important part of Chinese sport, it concerns economic prosperity, social stability and harmony. So, the period after the "18th CPC National Congress" is particularly critical, to research mass sports development in our country at this time has important practical significance for building well-being society in all-round way.

\section{THE CONNOTATION OF "BUILDING WELL-BEING SOCIETY IN ALL-ROUND WAY”}

Building well-being society in all-round way is one development stage of Chinese characteristics socialism. In October, 2007, in the report at the 17th national congress of Chinese Communist Party, Comrade Hu Jintao pointed out that by 2020, the goal of comprehensive construction well-being society is realized, our country with long history of civilization and large country of developing socialist, will become country of basic implementation industrialization, comprehensive national strength being markedly enhanced, overall scale of domestic market among the world top countries, become country of general improvement of people's wealth, life quality being improved significantly, good ecological environment, become country of people enjoying more fully democratic rights, of higher civilization quality and spiritual pursuit, become country of more perfect regulations in various aspects, full of vitality and stability and unity of society, become country of more open, more affinity, greater contribution to human civilization. To build well-being society in all-round way adheres to the basic principles of "inclusive growth", the core idea is the people's better life, the further development of modernization. So, in the period of "Twelfth Five Year Plan", development of mass sports in China must be both based on reality, but also take into account the future.

\section{AN OVERVIEW OF DEVELOPMENT OF MASS SPORTS IN CHINA}

Since the founding of new China, along with the different stages of economic and social development, compatible with the economic development level, social background, management system in certain historical period, mass sports work has presented one after another high point, A series of policies, systems and planning were introduced with distinct era characteristic, the state has promulgated the "National fitness program outline" and "Regulations of the national fitness program" and other documents, they has played a huge role in promoting development of mass sports. The mass sports work has made significant increase in our country, whether strengthening consciousness in the sports, popularity of national fitness, construction of sports facilities, carrying out sports activities or government funding on sports, all has made considerable progress. After nearly two decades of exploratory practice, we has preliminarily established basic framework of mass sport institutional system with Chinese characteristics, of mass sports supporting system and security system, the road of mass sports reform with Chinese characteristics, or the road of system innovation and construction of mass sports, is forming[1]. Of course, the mass sports in China still have some outstanding actual problem affecting its own development, it is urgently to be improved and resolved in recent years.

\section{PROMINENT PROBLEMS OF MASS SPORTS DEVELOPMENT IN CHINA}

\section{A. Role Orientation of Mass Sports in the Promoting Process from Large Sports Country to Strong Sports Country}

Mass sports development level is one of basic standard of measuring and judging strong sports country, from Chinese development of mass sports in current situation, China can not be called strong sports country. In Post-Olympic era, the government sports policy must be inclined to mass sports, at the same time, government can not give up development of competitive sports. In recent years, the development of mass sports in our country has made great progress, from type, form of sports activities, population quantity of regular physical activity, frequency and number of mass sports contests, the scale, size of sports facilities construction and other various aspects, our country can achieve the standard of large mass sports nation. However, there are still many constraints in the development of mass sports: sports population growth and quality of training is uncoordinated; the ethnic characteristics of national fitness has fewer 
international exchanges, and weak impact; mass sports development presents regional imbalance situation; the resources provided by society can not meet growing demand for physical training[2]. In the face of present situation of mass sports development behind athletic sports development, it is particularly important to clear understand and position mass sports development.

\section{B. Significant Difference between Urban and Rural}

The development of mass sports in urban and rural areas is very unbalanced, farmer sports development obviously lagged behind citizens sports development. Specific performance is: the consumption level of urban-rural differences in physical exercise, resident physique differences between urban and rural, urban and rural difference in masses sports investment. In addition, the development of mass sports in urban and rural areas, an insurmountable obstacle is poor sports resource, not only lack of facilities equipment, also includes poor sports information, sports technology, sports talents, sports knowledge and sports skills. In the current situation with limited national strength and multi-demand, it is impossible to invest huge sums of money on hardware facilities equipment in majority of villages, it is also impossible to appoint more external social sports guiding force to majority of rural communities. In addition, it obviously exists problem of unbalanced development of mass sports from the east coast to central and western regions in our country.

\section{Public Service System in Mass Sports}

The national fitness public sports service system is basic, most important part of construction of relatively perfect national fitness system, compared with competitive sports, the public service of mass sports in China is still at a low level, it urgently needs to be improved and enhanced. This is manifested in: lack of public financial support; in government public sports finance system, there was no category of mass sports funding, mass sports fund is included in "other undertakings of sports fund"; There is no specific professional and technical personnel to serve national fitness. In national sports talent category, there is no category of mass sports professional; Public sports facilities is the most basic public sports resource of mass sports, it has no statistical categories, there is no data of public sports facilities of mass sports. Although our country has done lot of work in the aspect of resources supply for national fitness public sports, and has made great progress, but the scale and level of public sports service, which can be equitably accessed to public, is still very low, there is still a big gap. It urgently needs to "grasp national fitness activities like grasping competitive sports", to focus on building public sports service system of mass fitness, and thus to gradually realize equalization of public service in term of mass sports, to promote social equality of mass sports [3].

\section{DEVELOPMENT STRATEGY OF MASS SPORTS IN CHINA}

\section{A. Adhering to Balanced and Coordinated Development of Mass Sports and Competitive Sports, Focusing on Mass Sports}

We must first realize the scientific development of mass sports in order to achieve the strategic objectives of strong sports country. The key of achieving development of mass sports lies in popularity of masses and level of participation extent. Secondly, there must be supported by level of development of mass sports, mass sports are a powerful gripper to improve residents' life quality and to realize "people's livelihood" project. In the face of present of situation mass sports development behind athletic sports development, we must realize that in the process of promoting construction of strong sports country, the development of mass sports is not only difficulty, but also priority. Only we have clear understanding and positioning on development of mass sports, we can pay more attention to development of mass sports, give more room for development of mass sports, make its contribution in the process of promoting strong sports country, and then make contribution to build well-being society. At the same time, we also should correctly understand and handle the relationship of coordinated development. Giving priority to development of mass sports, and effectively putting emphasis on basic task of strengthening people's physical fitness, continuing to maintain sustainable development of competitive sports after the Olympic Games in London, making best grade in Olympic Games and other world competitions, with sports management, sports law, sports industry, sports science and education and sports spirit as support and security, to effectively form the situation of coordinated development, simultaneously advancement of mass sports and competitive sports.

\section{B. Adhering to "Inclusive" Growth, to Balance Urban and Rural Development of Mass Sports}

On September 16, 2010, at the Fifth APEC Human Resources Development Ministerial Meeting, President $\mathrm{Hu}$ Jintao pointed out that the fundamental purpose to achieve inclusive growth is to make economic globalization and economic development benefit all countries and regions, all people, to realize coordinated development of economy and society in sustainable development. "Inclusive growth" is a basic principle to be adhered in our country to build well-being society in all-round ways, and its core is coordinated development and common development. The core target of implementing development strategy of urban and rural mass sports is to narrow gap between urban and rural mass sports, so that farmers can enjoy the same sports rights and treatment with urban residents, thereby reducing urban-rural difference of development of mass sports. Specific performance is: scientifically determining plan of urban and rural mass sports development. Through institutional innovation, resource integration, optimizing allocation of development elements of urban and rural mass sports to achieve comprehensive, coordinated and sustainable development; deepening reform to establish unified and coordinated governing organizations of urban and rural masses sports; playing the bridge role of sports in small towns to promote joint development of urban and rural mass sports.

Adjustment of development policy and priority of mass sports, giving priority to and focusing on fostering rural sports in development of urban and rural mass sports to gradually narrow gap of urban-rural sports; conducting sports and cultural activities of urban-rural integration, whole of urban and rural area to promote harmonious development of urban and rural sports, to narrow dualistic structure and realize "containment" of urban and rural development and regional development. 


\section{Adhering to Human-oriented, and Constantly Develop and Perfect Public Sports Service System of Mass Sports}

In April 2009, the State Council promulgated the "National Human Rights Action Plan (2009-2010)", it is the first to develop national planning with theme of human rights, from two aspects of cultural rights and healthy right, the text pointed out that "carrying out national fitness movement, amplifying mass sports organizations, perfecting national fitness system and establishing the public sports service system "is part of national human rights action plan. In the same year, the promulgation of "National fitness regulations" and the setup of "National Fitness Day", is marked that mass sports in China has entered new development stage [4], also marked that mass sports work has entered towards legalization, standardized and scientific. Fully implementing new cycle of "National Fitness Program "with national fitness day as carrier, to actively promote national fitness activities to be extensively developed, and to build more perfect national fitness service system, to utilize existing physical resources. To accurately determine government's main role in construction of strong sports country, adhering to principle of public welfare of mass sports, to increase capital investment on mass sports, to increase investment in grassroots sports facilities, to carry on scientific management of sports stadiums, improving usage of sports stadiums, to link usage of sports stadiums with management performance of institutions, to service for national fitness, to be human-oriented, and constantly develop and perfect public sports service system to meet people's growing health needs.

\section{CONCLUSION}

In a word, under the guidance of spirit of "18th CPC National Congress", thinking and research of development strategy of mass sports, putting forward scientific and reasonable development way, which is particularly important and of certain practical significance.

\section{REFERENCES}

[1] Dong Xinguang. Study of development of mass sports in China in nearly 15 years $[\mathrm{J}]$. Journal of sport culture Tribune, 2010, $10: 1-6$.

[2] Tian Yupu. Efforts to achieve coming into strong sports country from large sports country[J]. Sports Science, 2009, 29 (3) : 5-6.

[3] Dong Xinguang. The strategic choice of Chinese mass sports development in next 10 years [J]. Physical Education, 2009 (6) 1-6.

[4] Writing Group of the State Sports General Administration. Chinese sports of 30 years since reform and opening [M]. Beijing : People's Sports Publishing, 2008:376 -380. 